\title{
BETWEEN ORGANIZATIONS AND INSTITUTIONS. LEGITIMACY AND MEDICAL MANAGERS
}

\author{
GORDON MARNOCH, LORNA McKEE AND NICOLA DINNIE
}

\section{INTRODUCTION}

This article focuses on how the National Health Service, as a major public service organization, operating in a dynamic environment and utilizing complex processes of human interaction to deliver health care, creates and manages legitimacy. During the late 1990s the NHS embodied a particular series of changes which demanded novel responses from managers, clinicians and service users in relation to governance and professional standards. Most challenging of all are the attempts being launched to exert influence over the organization and management of clinical services, through clinical governance systems which create 'shared forums' for quality improvement (Scottish Office/Department of Health 1998). The emphasis here is to draw upon theoretical constructs of legitimacy and discourse as organizing schema for making sense of such change processes. The role of doctors who assume managerial duties will be examined as a prominent feature of the reform programme.

The problem of sourcing, building and maintaining legitimacy in the NHS is viewed through the new medical managers' representations of their role in the devolved management structures of the NHS in the 1990s. The new medical managers are clinicians who take on a management position within NHS trust organizations. As argued elsewhere the NHS has been for the first fifty years of its life, essentially a federation of professional tribes, each with their own social practices and inclination to attach different subjective meanings to health care processes (Hunter 1994). The new medical managers are seen as occupying a position between the organization that is the NHS trust and the profession-based institutions. Their part in creating an integrated corporate form of legitimacy is of some importance for the NHS in the next century. The developments under examination may signal a radical departure from earlier organizational practices, which relied 
on finding accommodations between professional tribes, whose insistence on high levels of autonomy was normally tolerated.

\section{THE NHS AND LEGITIMACY}

The NHS has traditionally relied on strong sources of societal legitimacy, derived from the extent to which its patients, employees and the public at large were persuaded of the integrity of familiar values and processes. In part, legitimacy was derived from the role played by professionals. Hogg (1999 p. 7) writes that 'doctors are expected to be experts, adhere to high ethical standards and not make mistakes'. However, the raw evidence contained in electoral surveys, also consistently demonstrates public support for the National Health Service as an organization. Nigel Lawson, a prominent politician of the right during the 1980s, described the NHS as the nearest thing the British had to a national religion (Timmins 1996, p. 453). In short, the NHS has seemed to deliver health care in the 'right way' and has, more than any other organization, fulfilled the principles of the postwar settlement struck by Labour in the late 1940s. It has been an organization, which has been capable of sourcing legitimacy from well-established social and organizational processes.

However, organizational legitimacy is a relative rather than absolute phenomenon, which requires mending and regeneration over time. It is clear that new technologies, treatments, modes of delivery, care settings and treatment philosophies are emerging fresh into the NHS at a rate which can challenge the basic principles of the UK health care system and it's public legitimacy (Harrison, Dixon, New and Judge 1997). This is not a problem unique to the NHS but is rather a worldwide phenomenon. Shortell for instance believes US health care is in a state of 'hyper-turbulence', with the institutional legitimacy of the American hospital being 'shaken at the core' by changes in payment systems, delivery systems, use of technology, professional relations and societal expectations. (Shortell, Gillies and Devers 1995). In the UK, health care planning 'rationality' is subject to major change (Harrison and New 1998, pp.67-70). Hospital planning certainties established in 1960s, for example one district general hospital to every 100,000 patients (Ham 1999, pp. 88-9), are breaking down, as exemplified by the readiness of professional bodies to discuss openly major reconfiguration of hospital services. The Royal College of Physicians for example, declared itself to be in favour of closing up to one-third of all hospitals in England over the next ten years (The Observer 1999). This issue of organizational legitimacy has been recognized elsewhere in the literature on health care organization and management (Harrison, Barnes and Mort 1997, pp. 5-6). The managerialism of the 1980s and 1990s while tightening up aspects of health service organization would appear to have failed to deliver a new source of legitimacy in the form of performance accountability and service quality assurance. While the NHS may indeed be better managed, this is not the perception held by the public or by many NHS 
staff, indeed it may even be true that the legitimacy bestowed upon the NHS in the past has been weakened by these changes.

It would be dangerous to conclude that the new public management introduced to the NHS is itself the cause of declining legitimacy; rather it should be acknowledged that a complex mix of social forces are at work. Learmonth (1997) has explored the issue of public criticism of NHS managers more fully, drawing attention to the problem of finding a form of management deemed to be 'appropriate' by an increasingly hostile public. Also it is widely accepted that in general the public exhibit less deference to professionals with whom they come into contact. While doctors may retain the ability to exert social authority over other professionals, they are also in the position of losing cultural authority in the sense that their definitions of reality and clinical decisions will not remain unquestioned by patients (Elston 1991; Harrison, Hunter, Marnoch and Pollitt 1992, pp. 119). The concept of the 'passive' patient awaiting the doctor's intervention is said to be increasingly redundant in the real world of medical practice (Jacob 1999, pp. 207-8; Williamson 1992, pp. 59-69); a view expressed by many of our respondents in the current study. A substantial literature exists on the subject of lay beliefs and non-compliance with medical advice (Williams and Popay 1994, pp. 118-39). The social processes associated with NHS provided health care, are doubtless subject to greater personal inquiry and scepticism than would have been the case in earlier decades, as identified by the Wilson Committee in it's review of NHS complaints procedures (Pickersgill 1997, pp. 7-13; Hogg 1999). These factors tend to become intertwined when the general condition of legitimacy is considered but can be expected to contribute to the public's sense of satisfaction with the NHS and health care provision. Mulligan (1998, pp. 200-1) reviewing British Social Attitudes Survey trends, records declining public confidence in the NHS. For example, 'dissatisfaction' rose from 26 per cent to 50 per cent between 1983 and 1996. At the same time, while 37 per cent of respondents rated health as the number one priority for extra public spending in 1983, this had risen to 54 per cent by 1996. Continuing party political criticism of management arrangements feeds and draws from this ambiguous relationship which has developed between the public and the NHS. Simple cause-effect conclusions should be resisted. Kneeshaw (1998, pp. 137-51), for example, has identified the paradoxical situation which exists between recorded levels of dissatisfaction with waiting times and actual waiting times in respect of out-patient services and casualty. Judge and Soloman (1993) have also drawn attention to the complex relations between public opinion, political context and media influence. The 'serenity' factor, a sense of public confidence and contentment in the health care service, identified by Bevan in the 1940s, has been undermined (Hennesey 1993, pp. 133-34). Over the past fifteen years it is likely that the adversarial nature of British politics concealed an emergent legitimacy problem, with both the electorate and opposition parties alternately ready to attach blanket blame on the Conservatives 
and their health care policies for perceived shortcomings in the way in which health services were being delivered. Both the public and the health care professions exhibit weakening trust in the organizational processes of the NHS at a time when more effort is being devoted to collecting and making available more supposed 'consumer friendly' service data than ever before. While at the same time utilizing more sophisticated systems of corporate governance than in any previous era. The inverse relationship between organizational activity devoted to what can be interpreted as exercises in legitimacy building and actual levels of legitimacy achieved has become apparent (Ferlie et al. 1996, pp. 197-9). While the NHS cannot be said to be in general crisis as a consequence of the factors described above, the capacity of the systems and processes to consistently generate legitimacy is impaired, implying an impending issue of sustainability.

This article seeks to address two key questions:

(1) What type of contribution do new medical managers make to the development of health services organization and to what extent do they provide a new source of legitimacy.

(2) What types of discourse are typically available and used by medical managers in making sense of the roles and responsibilities they have assumed?

\section{THE NEW MEDICAL MANAGERS, DISCOURSE AND LEGITIMACY}

Legitimacy although dependent on a range of factors of a political, technological and administrative nature, requires the verbal reasoning, explanation and argument of discourse to be activated as a management resource. At the simplest level, discourses are systems of knowledge which 'codify techniques and practices', expressed in dialogue, either verbal or in text or both (Harvey 1989, p.45). In a review of the differing definitions of discourse developed in the work of leading cultural theorists, Macdonnell (1986) notes that it is a common focus on the institutional nature of discourse which binds these contributions together. It is the linkage between different institutions and social practices in the development, maintenance and circulation of discourses which is of interest in this present study (Mills 1997, pp.6-12). Managers and clinicians although employed by the same organization - the NHS trust - also belong to professional and specialtybased institutions. In common usage the terms organization and institution are generally used interchangeably. However, in the present study, NHS organizations comprise budgets structures, hierarchies, roles and rules, while institutions refer to the profession-based social constructs influenced in character by conceptions of interest, consciousness, conventions, routines, habits, formal organizational rules and informally and voluntarily constructed rules, cultural beliefs and patterns of cognition (Scott 1995, pp.xv-xiv).

The discussion which follows, addresses the impact on organizational legitimacy made by a new class of NHS organizational players - the clinical 
directors - whose identification with 'corporate' NHS trust organization may be tempered by a stronger sense of 'belonging' to professional/ specialty-based institutions. Analysis is based on interviews with clinical directors in which they discussed management as a social practice and gave us an insight into the subjective meanings placed on the roles and responsibilities they have assumed in the contemporary NHS. The impact of the 'clinicians into management' policy in shifting the discourse into an arena where mutual understandings and terms of reference are shared by lay managers and clinicians alike, is considered through reference to dialogues recorded with clinical directors, chief executives and business managers. The intention is to view the role they are playing, through a form of discourse analysis which identifies their relationship to sources of organizational legitimacy.

In establishing the context of this exercise it should be noted that the NHS has traditionally been controlled through two quite distinctive types of order. The first has its origins in Treasury rules, 'comptrol' and principles of public probity (Marnoch 1996, pp.1-25). A predominantly 'administrator dominated discourse' allowed government to legitimize a particular process of resource allocation in the health care policy area. A second type of order evident in the NHS relied on principles of 'professional control' embedded in clinical practice. This activity in turn produced it's own often apparently separate and distinctive discourse. A third discourse was also required whereby problems unresolved in either administrator or clinical domains could be engaged. Generally this third arena of discourse would be dominated by the higher level lay administrators and doctors with training in the branch of medicine referred to in the UK as 'public health'. In effect it was possible to discern three distinctive 'interpretative communities' or institutions, each with their own distinctive positions and associated dialogues (Kumar 1995, p.131). Corporate-based organizational discourse as such did not exist, in the sense of there being a flow of interweaving dialogues carried on between the three types of NHS staff discussed above. The NHS it appears, is not unusual in this respect when comparisons are made with other health care systems. A recent study by Degeling, Idema, Hill, Kennedy and White (1998) places a great deal of stress on the evidence found to support the existence of powerful professional sub-cultures in hospitals located in both Australia and England. Cultural values such as 'reciprocity, loyalty, trust and solidarity' are thought to 'render medical clinicians unavailable to the individualising and disciplining strategies which characterise management practice in commercial and industrial settings'. The extent to which the NHS embraces a complex mix of professional and managerial sub-cultures and the manner in which separate discourses emerged over time, reflects a lack of inclination on the part of government to challenge professional autonomy. The subject of ideological conflict in the NHS consequently is a well-established research subject (Harrison et al. 1992; Currie 1997). Research analysing the obstacles to cultural change in 
the NHS is also common (Hill and McNulty 1998; Shafi and Munro 1998; Currie 1998). In broader terms, a debate continues as to the credibility of management driven 'culture change'. In a seminal article on this subject, Meek (1988) took a critical view of the propensity for the 'culture management school' to treat the norms, values and beliefs of organizational members as malleable variables in the hands of effective managers. Meek's conclusions seem particularly apt in relation to health care organizations where powerful well-established sub-cultures exist. For example, attempts to corporatize hospital organization may be seen as rational when derived from a management-dominated discourse but alternately might also be seen as the politically driven removal of 'medical ascendency' over other clinical groups when observed from the viewpoint of either doctor or nursingbased sub-cultures (Degeling, Kennedy, Hill, Carnegie and Holt 1998, pp. 253-70). There is no presumption in this article that culture is 'manageable', nor is there an attempt being made to treat discourse as something which is staged and directed on management's terms. Nevertheless discourse is a contributing factor to the evolution of organizational culture/sub-cultures and in the case of the NHS was 'influenced' by contextual factors such as the managerialist informed policies followed by government in relation to the NHS. Certainly from the mid-1980s attempts were being made to centre the organization of the NHS around a single management dominated discourse. That the impact of this 'influence' was unpredictable in respect of fostering common organizational aspirations goes without saying. The managerialist and then market-dominated eras failed to impose an ideology or 'mindset' on the terms upon which discourse took place in the NHS. This had major consequences for organizational legitimacy.

Legitimacy is achieved when practical activities are ascribed a 'normative dignity' through their accordance with prevailing social norms (Berger and Luckmann 1967, p. 93; Weber 1968). That is to say, activities are embraced as part of a widely endorsed model of how a society is supposed to 'work'. Meyer and Scott (1983, p. 201) identify legitimacy even more simply as cultural support for an organization.

For the NHS to be culturally and politically legitimate requires that its activities are perceived as 'desirable, proper and appropriate' within the prevailing context of society (Suchman 1995, pp. 571-85). Following Suchmann's work on legitimacy, the NHS can be seen to depend on distinctive pragmatic, moral and cognitive sources. In so far as a 'strategic approach' to legitimization can be said to exist, the dominant force of reason has been expressed by government in terms of justifying the new NHS through 'performance' symbols such as league tables and lists of waiting times, presented as substantive outcome measures. This type of activity was intended to provide a direct source of pragmatic legitimacy (patients' selfinterest). The creation of public limited company-style NHS trust hospital boards, served by non-executive directors recruited from industry was also thought to add a further element of cognitive legitimacy, in the sense of help- 
ing NHS hospitals take on recognizably business-like practices (looking the part). Clinical directors, on the other hand were potentially a source of moral legitimacy, they alone amongst the participants in the totality of the anticipated new managerial discourse had access to a form of legitimacy that derives from a life of 'stethoscopes, rounds and gowns' (doing 'things the right way' in the eyes of patients).

A complex discourse surrounds the creation of legitimacy with respect to health service organizational form and practice. However, given the centrality of medical decision making to the 'business' of health care provision, it is difficult to envisage the form of a unifying NHS, if clinical directors or other medical leaders are not central participants (for example Mechanic's (1991) treatment of the 'de-professionalization thesis provides a useful perspective on this issue developed in the context of US health services). The range of factors influencing the new medical management and the progress made by clinical directors in developing reason, language and concepts which impact on the legitimacy of the contemporary NHS need to be examined closely.

\section{FROM MANAGERIALISM TO CLINICAL GOVERNANCE}

New Labour's approach to NHS reform as described in the White Papers for Scotland and England, Designed to Care (Cm 3811, 1997) and The New NHS: Modern and Dependable (Cm 3807, 1997), establishes a commitment to developing a network of integrated clinical services which deliver seamless care. Current health services policies reflect contemporary thinking on organizational design, in which flatter, less hierarchical, forms are preferred and associated with encouraging collaborative behaviours and enhanced organizational learning. Previous change programmes based on the 1983 NHS Management Inquiry and the 1989 White Paper Working for Patients ( $\mathrm{Cm}$ 555) also stressed the theme of devolved management (Harrison, Hunter, Marnoch and Pollitt 1992; Pettigrew, Ferlie and McKee 1992; Strong and Robinson 1990). In the 1980s it was hoped that clinicians, particularly senior doctors, could be incorporated within the management process through appointment to general management posts. In practice this was rarely realised. Clinician participation in management was also equally limited, in the management budgeting project, an exercise in bringing together systems for monitoring and controlling service outputs and costed inputs. Later re-launched as the resource management initiative, greater emphasis was placed on devolving resources in an attempt to commit decisions to the level of the individual consultant (Pollitt, Harrison, Hunter and Marnoch 1991; Packwood, Keen and Buxton 1991). Devolved management, in this context, meant that clinical teams would become attuned to key resource information describing different patterns of treatment being offered to patients; and choices would be made between clinical approaches. This, in turn, would allow for a stronger clinical input to flow into the resource planning process and stronger central control over costs and quality would 
thus be achieved. This was a change programme aimed at removing the rigid barrier that existed between clinical decision making and management decision making. Later in the 1990s, following the implementation of Working for Patients, self-managed provider units were required to be in a position to tender for contracts. This, in turn, implied a need for greater control over clinical staff and their use of resources in delivering services to contractually bound costs and standards. In response, trust leaders were encouraged by representative bodies such as National Association of Health Authorities and Trusts and the Institute of Health Service Managers to adopt an organizational model based on clinical directorates as a means of linking corporate management to clinical activity.

The origins of clinical directorates are to be found in responses made by clinicians at the grass roots. Following the failure of a temporary closure of a hundred beds at Guy's Hospital London in 1984, a group of clinicians began to take an interest in identifying a more systematic method of operational management at specialty level. The outcome was an agreement to experiment with the 'Johns Hopkins' model of medical management based on department sub-units called clinical directorates (Chantler 1993). With clinical directorates having been established in virtually all the National Health Service trusts by the early 1990s, the British Medical Association, the Institute of Health Service Management, The Royal College of Nursing and the British Association of Medical Managers $(1993,1996)$ jointly authored two reports providing a consensus statement on what is thought to work in clinical management. (The British Association of Medical Managers was formed to represent the new category of clinicians with a contractually specified management responsibility.) The report identified clinical directors with the role of co-ordinating and developing patient services. It advised that clinical directors should have managerial control over nursing and paramedic staff and that they should be supported by a nurse manager and business manager with appropriate administrative and clerical staff attached to the directorate. It was stated that the business manager's role should be concentrated on administration, information technology, budgeting, planning, records and staff. Devolved management at this point took a distinctive organizational identity and began to realize the ambitions of earlier reformers. Implicitly these changes demand a new basis for organizational discourse.

In what may be interpreted as a response to the problem of declining public and professional trust in the organization of health care in the UK, the 1997 White Papers restated the 'doctors into management' drive in the context of the organizational arrangements and practices associated with 'clinical governance':

The Government will amend Trusts' statutory duties to make explicit their responsibility for quality of care. This will need to be taken every bit as seriously as the existing financial responsibilities ...., The intention 
is to build on existing patterns of professional self-regulation and corporate governance principles, but offer a framework for extending this more systematically into the local clinical community, and ensure the internal 'clinical governance' of the Trust (Scottish Office 1997).

In short chief executives are to be made accountable for clinical quality in the same way, that they are accountable for financial performance and probity. Clinical governance, will according to the British Association of Medical Managers (the NHS doctor-managers 'trade union'), require chief executives to develop the same type of close relationship with doctor-managers, as they tend to have with their directors of finance (BAMM 1998). Hackett and Spurgeon (1999) believe that trusts will be required to change fundamentally their systems, processes and performance management mechanisms. They conclude that trust chief executives will need to manage culture change actively to deal with powerful individuals and coalitions. Wattis and McGinnis (1999) draw attention to the likely inadequacies of NHS information infrastructure in respect of supporting earlier clinical audit initiatives and see the implementation of clinical governance as requiring a new approach to 'knowledge management'. The new set of reporting requirements, along with the relationships involved in the delivering high quality clinical services, require a new clinical centred organizational discourse based on an organizationally integrated and interdependent appreciation of health care (Marnoch and Ross 1998). This has been recognized by the participants in the policy implementation process. The Institute Health Services Management, for example, see a need for organizational development programmes to take place in order that lay managers are trained to better understand the substance of clinical issues (IHSM 1999, p. 30). The NHS Executive have also re-stated the principles and criteria behind continuing professional development (CPD) in terms of organizational integration in response to the implementation of clinical governance. In particular an emphasis is placed upon establishing CPD as a 'partnership between the individual and the organization' in the context of a 'learning culture' (Department of Health 1999).

\section{BACKGROUND TO CLINICAL DIRECTORS STUDY}

The ESRC funded study, from which data is drawn, represented a continuation of earlier work examining management reforms and organizational change in the NHS. (Pettigrew, Ferlie and McKee 1992; Harrison, Hunter, Marnoch and Pollitt 1992). Both studies accentuated the notion of 'professional tribalism', a metaphor used to describe the sub-culture based and frequently adversarial nature of organizational relations. Findings also confirmed the extent of separation between managerial and clinical domains discussed earlier. These factors were found to be major barriers to the implementation of change processes associated with general management in the mid-1980s. Doctors typically remained disengaged from management 
reforms. Following the market-orientated reforms of the early 1990s, the problem of empowering doctors to contribute to general management was further elaborated by Marnoch (1996). Here, the emergent breed of medicalmanagers known as medical directors and clinical directors were discussed in relation to the 'new NHS'. Medical directors are statutory members of trust boards created in the 1990 NHS and Community Care Act. Clinical directors are clinicians who have taken on a management role on a parttime basis. They hold a budget and managerial responsibility for a specialty or group of specialties/sub-specialties. The Aberdeen study centred on clinical directors, who as practising clinicians, were an entirely new breed of medical manager. The project allowed the research team to address key unresolved questions (Fitzgerald and Sturt 1992; Burgoyne and Lorbiecki 1993). A key aim was to discover whether the actual behaviours of clinical directors supported an emergent organizational form based on a radical mixture of decentralization, empowerment and market-driven networking, or alternately, a traditional line management system associated with global budgetary control (Marnoch, McKee and Dinnie 1997a, 1997b; Hecksher and Applegate 1994, pp. 1-14) The report which followed (Marnoch, McKee and Dinnie 1997a) addressed a number of specific questions concerning the precise roles assumed by clinical directors: their role in strategy; their participation in contracting and the internal market; their influence over quality of care; their budgetary responsibilities and span of control; their contribution to organizational and clinical change; the interface with other levels of NHS management and clinical colleagues; and their management aspirations, orientation and style. Comparison made between individual clinical directors and in turn comparisons made between different trusts, provided an opportunity to comment on diversity or consistency of implementation of directorate structures across Scotland.

The study concluded that clinical directors had not been fully absorbed into 'traditional' NHS line management/global resources control systems (McKee, Marnoch and Dinnie 1999). The problem of integrating and organizing those responsible for medicine and those responsible for money remains a problem (Dawson, Mole, Winstanley and Sherval 1995). Clinical directors rarely dominated devolved budgets and were not typically creating new strategic arenas. They often remained wary of activities which would either distance them from their clinical colleagues or challenge clinical autonomy. This in turn inhibited the impact which clinical directors made on the change process associated with the NHS reforms of the 1990s. (An inquiry carried out by the Audit Commission (1995) identified a range of problems associated with the lack of management control over operational processes in NHS hospitals). However, the report also recorded a good deal of evidence indicating that clinical directorships provided professional satisfaction, enhanced management competency and development for many clinicians. The possibility of constructing a new form of devolved management based on clinician-managers was therefore encouraged by the 
adoption of the clinical directorate form. Other researchers confirm this finding (Fitzgerald and Dufour 1997; Ong, Boaden and Cropper 1997). Indeed several instances were recorded where clinical directors were forging a new hybrid domain where traditional managerial and clinical roles and responsibilities were becoming blurred. The interest in legitimacy and discourse consequently emerged from the analysis of quantitative and qualitative data gathered.

\section{METHODS}

The study comprised of a survey of all clinical directors in Scotland and follow-up interviews with a sub-sample of clinical directors, medical directors, chief executives and business managers from selected directorates in six NHS trusts during 1995-96. A total of 240 clinical directors were in post at the time of the postal survey located in 39 NHS trusts. (Not all medical managers in devolved management systems are called 'clinical directors'. For our purposes clinicians holding budgets for staff were regarded as the subjects of our programme of research.) Of the 240 questionnaires that were sent out, 157 were returned (response rate 65 per cent). Of the 157 which were returned 10 were disregarded at this stage of the research as they had been sent to individuals who fulfilled the post of clinical director although they were not medically qualified leaving a total sample size of 147 . After the population is adjusted to 230 this gives a response rate of 68 per cent (Marnoch, McKee and Dinnie 1997a). While there are some significant organizational differences between NHS health care services in Scotland and England, there is no evidence from existing studies of medical behaviour and hospital sub-cultures to suggest that the roles and responsibilities of the clinical directors examined are systematically different from those elsewhere in the United Kingdom. The validity of attempts to generalize from the Scottish-based study are also encouraged by the earlier research experiences of Marnoch and McKee in England.

Drawing on full tape recorded transcripts of some forty lengthy face-toface interviews with clinical directors, medical directors, chief executives and business managers drawn from a sample of Scotland's NHS trusts, the paper explores the factors which are structuring the emergence of a new form of organizational discourse involving clinical directors. The qualitative data gathered in the study is used here to indicate the extent to which the discourse of health care management has moved on to a level from which mutually shared legitimacy building concepts have emerged.

\section{A STORYBOARD APPROACH}

Following practice established for ethnographic research we adopted what Watson and Harriss (1999, pp. 1-26) have described as the 'empty story board' approach. As interviewers we imposed only a very loose framework on the discussions with our respondents. Instead of asking direct questions of a factual nature, we were more concerned to listen to clinical directors' 
stories about the job and the organization they worked in as guides to their self-awareness as 'emergent managers'. The clinical directors were the central characters in the 'plot' that took shape around four dominant themes: politics, budgeting, monitoring and organizational structure. On the basis of the researchers enhanced contextual information, derived from our knowledge of recent NHS organizational history and the vantage point gained as observers in a large number of institutional settings, we concluded that these themes best convey clinical directors engagement with management as a process. Discussions of each theme are based around an examination of interview transcripts. Representative extracts have been used to give an impression of the world view adopted by clinical directors in relation to the management process.

\section{POLITICS}

The tendency for the discourse of medical management to wrap itself around political issues was very apparent. For instance on one level it was clear that a government policy of promoting 'hair shirtist' economy drives, which was in vogue during the period of the study, drew the discourse towards explanations of how management costs could be reduced. An illustrative example of the ready justifications and ability to quote facts and figures offered in response to this political demand, is contained in the following exert form an interview with a clinical director:

I know the ME (Management Executive of the Scottish NHS) are concerned about money, the ME are wanting to see management costs reduced, let's be quite blunt about this ... I have done away with that grade 4 post devolved it down to two other people who are now grade 4s but I have effectively done away with the post and I have put on a business support officer who costs about a third, so in fact in management terms I have made a huge saving in this directorate. Our real up front management costs are business support officer and me, total cost about 15,000 a year Where else could you run a 2 million pound organisation for 15,000 (clinical director 25).

On a different level the clinical directors working in teaching hospitals, would in many cases articulate a sophisticated line in political analysis, to describe the path that had to be trod between the power lines running between the Deans of the Medical Schools and professors heading up university departments. An example:

Well you know I think the university system is absolutely diabolical, you know you are a professor, you have got complete rights to do anything ... but you and I both know that is not the way proper management works, you want to do away with that, but that is the way this place was, basically there was a prof and the rest just did what the prof said. ... but the clinical director is sitting say with a three year contract or no contract at all (clinical director 15). 
A third type of political discourse over the NHS management hierarchy, typically stimulated clinical directors to theorize at length:

I think the people here take the ME (Management Executive) and their requirements incredibly seriously. They see that as their main role really, and they're not entrepreneurs in the sense that saying 'Okay, we know the ME says that, let's see if we can get round it ... They're very straight down the straight and narrow (clinical director 6).

.... the role of the Trust Chief Executive and the Trust Finance Officer is to actually comply with the requirements put down by the ME (Management Executive of the Scottish NHS) .... I mean the ME are bumptious, imported, failed business men really aren't they (clinical director 12).

A fourth type of politically orientated discourse revolved around the recognition that doctors are not traditional team players. For instance one interviewee talked about his role in attempting to break down the barriers between surgery and medicine. The interviewer went on to ask him if this meant that he was in fact attempting to create new clinical processes? After a moment's consideration, he concluded 'no', explaing that his role was really akin to that of a referee - other people played the game and he had to take decisions every now and again.

A generalized belief in the inevitability of politics in the modern NHS was evident. According to one respondent the NHS of 1948 was a semimilitary organization, the Medical Superintendent and the Matron had genuine authority which people who had returned from the armed forces were comfortable with. The 'chief system', where a consultant pecking order was recognized, worked well in his view. The NHS had a 'slim structure', there was a Clerk of Works and a Hospital Secretary and management was very low cost. This he explained gradually broke down. A tacit recognition of pluralism, it's inevitability and consequences, featured heavily in accounts of management provided by clinical directors.

The social practices associated with these political themes can readily be seen to mitigate against the development of an integrated organizational discourse and therefore provides little material for legitimacy building. The notion of the NHS producing separate clinical and managerial discourses stills holds good, when clinical directors discuss politics.

\section{BUDGETING}

Budgeting and finance was expected to be a major focus for the clinical directors. The potential for Resource Management Initiative based systems to integrate clinicians and lay managers in decision-making processes has been obvious since the mid-1980s. Avoiding direct reference to the RMI, the study tried to identify evidence of clinical directors being in a position to conduct a dialogue on the resource consumption patterns of their direc- 
torate colleagues in a fashion derived from systematic information gathering. This type of resource-based discourse was not obviously occurring in any of the NHS trusts examined in the qualitative data gathering stage of the Aberdeen study. In the single site where there had been a significant amount of energy devoted to establishing a resource management system, it was clear that the exercise had been treated as a one-off knowledge generating project, rather than the basis for a new type of organizational discourse.

I think the principles are sound. What we found was that RMI tried to cover an all-pervasive thing that the RMI project group was almost then a shadow trust board and was trying to take powers unto itself, but those were not appropriate. So I think in terms of our own project giving us money to move forward into the hidden technology of information and management, for example, getting financial management systems in place, helping us to support organizational development with the clinical directors, I think it was super .... but we came to the conclusion that it was really operating in parallel and that what we needed to do was to scrap it (clinical director 10).

Budgeting and finance feature far more frequently in the lives of clinical directors as sources of bureaucratic frustration, as illustrated by a typical discussion of the role of finance directors:

.... I personally believe it's because they're cautious individuals, particularly the Director of Finance. I find that most Directors of Finance are pretty computerised individuals anyway, you know and they're very conscious of the need for financial accountability. ... I think that that's a reflection on management in general, that if you're given a finite sum of money then you're supposed to work within the framework of your budget. What it doesn't do, of course, as far as we're concerned is provide any incentive (clinical director 16).

The devolved budgeting experience is failing to provide a focus for a corporate organizational discourse to develop and in that sense provides no new source of legitimacy. Neither pragmatic (self-interest) nor cognitive (looking the part) legitimacy could be seen to be generated around the clinical directors' role in the budgeting process.

\section{MONITORING}

One of the classic tasks associated with a line management structure is the monitoring of a subordinate's performance. The process of monitoring helps generate cognitive legitimacy, because it is an expected part of organizational life and therefore evidence of such activity confirms integrity of purpose. The clinical directors tended to discuss monitoring in one form or another during interviews. In short there is at present little evidence of clinical directors assuming performance monitoring-type roles. In a sense 
the terms of the medical management discourse are defined by the available information. With an absence of systematic clinical data gathering systems, there is a lack of inclination to single out poor performing colleagues as explained below:

.... I would have to tell you that our information systems are almost too poor to ever confront me with that (problem), we are primitive in terms of budgetary information, activity information, but if there was an outlier of that kind, three standard deviations away from the mean, I wouldn't have any problem about speaking to him. Whether it would influence him would depend a wee bit whether he was amenable but it wouldn't bother me to confront someone and say look asthmatics are in here for 10 days and everybody else is in for 2 days. Why is that? I haven't had to deal with any issues like that, because we are not highly sophisticated at looking at individual practices and comparing them (clinical director 25).

It should also be noted that the clinical directors have a limited power base in so far as they might wish to launch actions against colleagues believed to be poor performers. The possibility of a middle-management style of discourse developing with directorate colleagues and 'senior' lay managers is unlikely to be fulfilled, a view expressed by many clinical directors:

.... my style is more presenting the problems to them and saying, 'Well what do you think we should be doing about it? How do you think we should...?' And hopefully, in a way, we need to try to lead them along the lines I think they should go but...I certainly don't come to them and say 'right...we're going to do this that and the next thing'. I much prefer them to come out with the problem and say 'have you any ideas how to deal with this'? (clinical director 7).

With greater pressure on NHS trust chief executives to 'guarantee' clinical quality the absence of a monitoring discourse in clinical directorates is a legitimacy threatening issue yet to be confronted.

\section{ORGANIZATIONAL STRUCTURES}

With a place in a line management structure appearing as either unfeasible or unattractive to clinical directors, positive articulations of contributions to the management of change tended to be wound up in the problems of finding appropriate ways of working in flat non-hierarchical teams. The directorate system was generally recognized as having facilitated stronger communication between lay managers and clinicians, as illustrated in the comments below:

I think that the greatest weakness of any of the previous systems were that, or was, that really the input from people such as myself into the then management structure was by letter, by telephone, it was very tenu- 
ous and I personally believe that it was completely unstructured (clinical director 17).

The clinical directors are now certainly 'structured' into management but not it would seem into a strategic orientated discourse. If clinical directors or other medical managers are not used to develop the corporate strategy of NHS trusts, there is a danger that increasing the direct involvement of the clinical directors in organization produces a rather negative reaction to management as a process. This is partly caused by the extent to which the clinical director's view of management discourse is filtered through their involvement with and immediate technical reliance on 'business managers', the title given to support staff located in directorates. Offering at best a type of 'middle-managers' perspective on organization, the business managers are failing to offer a conceptual role model for clinical directors. With relatively few opportunities for interacting with the chief executives and medical directors, who are operating in a discourse created in part by the actions of government and carrying with it a prestige of sorts, the clinical directors may be in danger of being suffocated under the weight of an unappetizing representation of the middle management process as conveyed to them through their business managers. While the need for a middle-management role is arguably still evident in aspects of health service organization (Wall 1999), a simple (in traditional management terms) scripting in of the clinical directors into NHS organizations, as players with typical middle manager's sensibilities was doomed to fail. The classic tasks associated with middle managers -the timely and accurate execution of operational activities - are made difficult or in some cases impossible, by the complex power relations evident in NHS trusts (Keuning 1998, p. 24). In any case from a legitimacy generating perspective there seems little to be gained from aligning clinicians with a lay manager-dominated discourse.

Even on a very basic level of facilitating 'bottom-up' communication few NHS trusts had succeeded in involving their clinical directors in strategy formation. In the six NHS Trusts, where detailed interviews were undertaken, just one case was discovered where a chief executive was making it a regular part of his day to meet with clinical directors for purposes of strategic planning and implementation. Significantly this took place in the smallest NHS trust examined. Size and proximity may be very significant factors influencing the condition of the organizational discourse involving clinical directors.

The extent to which a devolved management structure based around clinical directors can produce a discourse for re-invigorating management processes used by the NHS is as yet unproven. Moral legitimacy 'doing things the right way' remains dependent on clinical practice and clinical discourse, while the demand to deliver a clinical governance quality guarantee faces chief executives with a greater need to use devolved management and clinical directors as the building block for a new form of 
organizational discourse. It is unclear if medical managers can generate an integrative discourse around their roles and responsibilities. The distinction between organizational and institutional-based discourses may be of key importance in understanding what is likely to happen. Doctors and nurses, though employed by organizations (NHS trusts), are also members of institutions. The organizational form taken by the NHS has changed frequently since 1947. Legitimacy may be far more securely rooted in institutional practices which define 'the way things are done', providing stability over time and a 'sense of place' (Lowndes 1996, p. 182). Clinical practice, the professionally accepted ways of dealing with patients (moral legitimacy), has arguably remained the foundation of health care service legitimacy in the United Kingdom, subject only to evolutionary change, unlike NHS organizations which have altered frequently. A tension has always existed in the NHS between organizational hierarchy and institutional patterns of power and influence (Frankford 1997, pp. 185-93; Alvesson and Willmott 1996, p. 33). Clinical directorates or other organizational means of scripting doctors into management are no quick fix in this respect. The NHS will need to convince powerful institutional groupings of the need for integrative discourse.

\section{CONCLUSIONS}

We began earlier by posing questions concerning the type of contribution, which the new medical managers make to the development of health services organization, including the extent to which they provide a new source of legitimacy. It was also intended to examine the discourses developed by them to make sense of their roles and responsibilities. Suchman's (1995) framework based on the notions of pragmatic, moral and cognitive legitimacy has been employed throughout as a means of organizing evidence generated from dialogues conducted with both medical managers and lay managers.

When the question of whether medical managers have been used profitably in establishing new sources of legitimacy is addressed, it is clear that any gains made must be set against the negative consequences of earlier health service reforms. The move away from command and control type of hierarchy, endorsed by both the 1989 and 1997 white papers, is consistent with the intention to reform the welfare state and place consumer preferences higher in the list of governance priorities and thus marking it would seem, a relative decline in importance of budgetary comptrol. The 'businessed up' organization needed in turn to be supported by new sources of legitimacy. In other words the logic of a move away from a hierarchical mode of governance towards a service mode, necessitated leaders of NHS trusts to attempt to derive legitimacy from strategically driven businessstyle activities. The 'storyboard' approach adopted here, provided an opportunity for clinical directors to describe their engagement with the business-orientated NHS. While the clinical directors have been written into 
the management process, the dialogues... which were recorded, fail to indicate the development of a strategically informed orientation in relation to delivering services in a business-like way. Indeed much of their representation of the role they fulfill is concerned with describing different types of political activities, which in turn are often wrapped up directly or indirectly in the budgetary process. This is indicative of a more generalized problem encountered in the NHS with the act of replacing budgetary control of the 'annual across the board percentage increment' type, with 'strategically informed' decisions over resource allocation (Joyce 1999, pp. 72-6). The NHS, in common with other public service organizations, is often guilty of 'talking strategy' but 'thinking incrementally'. The market experiment made little impact on this tendency, having for example created few apparent opportunities to develop exchange-based pragmatic legitimacy around the contracting process.

In so far as clinical directors had contributed positively to a process of reconfiguring health services organization in response to opportunities to deliver services in new ways, various positive findings were made. For instance several clinical directors were clearly trying to make sense of their role by thinking and acting in non-partisan ways, effectively rejecting the role of departmental delegate to an annual round of budget allocation by political resolution. However, this is encouragement for the future rather than a realization of 'integrationist' ambitions in the present. The NHS remains a divided organization, which is sustained by a compartmentaliszed discourse, seperating the managerial from the clinical. While traditional assumptions which informed the organization of health services are rapidly becoming redundant, the strategic management of the clinical complex - the management of the technology, knowledge, finance and skill required to exploit new possibilities in medicine - was not a subject which clinical directors tended to raise unprompted. Our evidence generally suggests that there is not as yet a sense of reciprocal understanding developing to embrace lay managers and clinicians in a discourse which will rebuild legitimacy around pragmatic, moral and cognitive sources of legitimacy.

The abandonment of the internal market and the current promotion of clinical governance and 'joined up' approaches to social policy may provide a new opportunity for medical managers to assert control over the discourse of organization. Medical managers have a potentially unique contribution to make in realizing legitimacy from health services practice. As important actors in developing processes of clinical governance, medical managers have a role to play in stripping back the mystique surrounding the management of quality of clinical care and rebuilding the legitimacy of the NHS on new terms. Medical managers may also yet become the central players in a form of corporate legitimacy management which has, as it's basic building block, discourse derived from the fulfillment of social exchanges involving broader groupings of health service professionals. Of key importance, given the emphasis on clinical quality assurance contained 
in the 1997 White Papers, is the ability of the medical manager to effect reciprocal understandings of the clinical process between managers, patients and doctors. This would seem crucial in remaking cognitive legitimacy for a new age of health care. The prospects for dealing with issues of clinical effectiveness, cost and patient involvement through the vehicle of clinical governance are in some part dependent on the development of an integrative discourse, the terms of which are still developing. At present, medical managers remain in the no man's land between management claimed organization and profession dominated institutions.

\section{REFERENCES}

Alvesson, M. and H. Willmott. 1996. Making sense of management. London: SAGE.

Audit Commission. 1995. The doctors' tale. London: HMSO.

Berger, P. and T. Luckmann. 1967. The social construction of reality. New York: Doubleday Anchor.

British Association of Medical Managers. 1998. BAMM Newsletter (March). Cheadle: British Association of Medical Managers.

British Association of Medical Managers, British Medical Association, Institute of Health Services Management and Royal College of Nursing. 1993. Managing clinical services. Cheadle: BAMM.

—. 1993. Principles into practice. Cheadle: BAMM.

Burgoyne, J. and A. Lorbiecki. 1993. 'Clinicians into management', Health Services Management Research 6, 4.

Chantler, C. 1993. 'Historical background: where have clinical directorates come from and what is their purpose?' in A. Hopkins (see below).

Cm 555. 1989. Working for patients. DOH. London: HMSO.

Cm 3807. 1997. The new NHS: modern and dependable. London: Stationary Office.

Cm 3811. 1997. Designated to care. Scottish Office/DOH. Edinburgh: Stationary Office.

Currie, G. 1998. 'Managerialism in the health service: partnership or conflict in a management development programme', Health Services Management Research 11 3, 192-9.

-. 1997. 'Contested terrain: the incomplete closure of managerialism in the health service', Health Manpower Management 23, 4/5, 123-32.

Dawson, S., V. Mole, D. Winstanley, and J. Sherval. 1995. 'Management, competition and professional practice: medicine and the market place', British Journal of Management 6, 3.

Degeling P., J. Kennedy, M. Hill, M. Carnegie and J. Holt. 1998. Professional sub-cultures and hospital reform. The Centre for Hospital Management and Information Systems Research, Sydney, University of New South Wales and Department of Social Policy, University of Newcastle upon Tyne.

Degeling P., R. Idema, M. Hill, J. Kennedy and L. White. 1998. 'Do professional subcultures set the limits of hospital reform', Clinician in Management 7, 89-98.

Department of Health. 1997. The new NHS: modern and dependable. London: HMSO.

Department of Health (NHS Executive). 1999. Continuing professional development: quality in the new NHS. Leeds: Department of Health.

Elston, M. A. 1991. 'The politics of professional power: medicine in a chanaging health service', pp. 58-88 in J. Gabe, M. Calnan and M. Bury, The Sociology of Health. London: Routledge.

Ferlie, E., A. Pettigrew, L. Ashburner and L. Fitzgerald. 1996. The new public management. Oxford: Oxford University Press.

Fitzgerald L. and Y. Dufour. 1997. 'Clinical management as boundary management: a comparitive analysis of Canadian and UK health care institutions', International Journal of Public Sector Management 10, 1-2, $5-20$.

Fitzgerald, L. and J. Sturt. 1992. 'Clinicians in to management: on the change agenda or not?', Health Services Management Research 52.

Frankford, D. 1997. 'The normative constitution of professional power', Journal of Health Politics, Policy and Law 22, 1, 184-221. 
Hackett, M. and P. Spurgeon. 1999. 'Culture, leadership, and power: the key to changing attitudes and behaviours in trusts', Clinician in Management 8 1, 27-32.

Ham, C. 1999. Health Policy in Britain. London: Macmillan.

Harrison, S., M. Barnes and M. Mort. 1997. 'Praise and damnation: mental health user groups and the construction of organizational legitimacy', in Public Policy and Administration 12, 2-16.

Harrison, A., J. Dixon, B. New and K. Judge. 1997. 'Is the NHS sustainable?', BMJ 314, $7075296-98$.

Harrison, S., D. Hunter, G. Marnoch, and C. Pollitt. 1992. Just managing: power and culture in the NHS. London: Macmillan.

Harrison, A. and B. New. 1998. Health UK 1997/98. London: King's Fund.

Harvey, D. 1989. The condition of post-modernity. Oxford: Basil Blackwell.

Hecksher, C. and L. Applegate. 1994. in C. Hecksher and A. Donnellon (eds.), The post bureaucratic organization: new perspectives on organizational change. London: SAGE.

Hennessy, P. 1993. Never again. London: Vintage.

Hill, S. and D. McNulty. 1998. 'Overcoming cultural barriers to change', Health Manpower Management 24, $1,6-12$.

Hogg, C. 1999. Patients, power and politics. London: SAGE.

Hopkins, A. 1993. The role of hospital consultants in clinical directorates. The Syncromesh report. London: Royal College of Physicians.

Hortell, S., R. Gillies, and K. Devers 1994. 'Reinventing the American hospital', Milbank Quarterly 732 , 131-60.

Hunter, D., 1994. 'From tribalism to corporatism: the managerial challenge to medical dominance' in J. Gabe, D. Kelleher and G. Williams, Challenging medicine. London: Routledge.

IHSM (Institute of Health Services Management). 1999. Devolved management in Scotland's new trusts. London: IHSM.

Jacob, J. 1999. Doctors and rules. London: Transaction Publishers.

Joyce, P. 1999. Strategic management for the public services. Buckingham: Open University.

Judge, K. and M. Solomon. 1993. 'Public opinion and the National Health Service: patterns and perspectives in consumer satisfaction', Journal of Social Policy 22, 3, 299-327.

Keuning, D. 1998. Management a contemporary approach. London: Pitman.

Kneeshaw, Jack. 1998. 'Does the public mind having to wait?' in Harrison and New (see above).

Kumar, K. 1995. Modernity and post-modernity, Oxford: Blackwell.

Learmonth, M. 1997. 'Managerialism and public attitudes towards UK NHS managers', Journal of Management in Medicine 11, 4, 214-21.

Lowndes, V. 1996. 'The new institutionalism', Public Administration 74, 2, 181-98.

Macdonnell, D. 1986. Theories of discourse. Oxford: Blackwell.

Marnoch, G. 1996. Doctors and Management in the NHS. Buckingham: Open University Press.

Marnoch, G. and K. Ross. 1998. 'Flags and badges - legitimacy in the new NHS', working paper.

Marnoch G., L. McKee and N. Dinnie. 1997a. Report to ESRC. Clinical directors: roles and responsibilities. Swindon: ESRC.

— 1997b. 'The conditions of power: the case of clinical directors and devolved management in the NHS.' Paper to Modes of organizing: power/knowledge shifts conference organized by Warwick University and Lancaster University, 3-4 April.

McKee L., G. Marnoch and N. Dinnie 1999. 'Puppets or puppetmasters' in A. Mark and S. Dopson (eds.), Organizational behaviour in health care: a research agenda. London: Macmillan.

Mechanic, D. 1991. 'Sources of countervailing power in medicine', Journal of Health Politics, Policy and Law 16, 3, 485-98.

Meek, V.L. 1988. 'Organizational culture; origins and weaknesses', Organization studies 9, 4, 453-73.

Meyer, J. and R. Scott. 1983. 'Conclusion: institutionalization and the rationality of formal organizational structure' in J. Meyer and R. Scott (eds.), Organizational environments: ritual and rationality. Thousand Oaks, CA: Sage.

Mills, S. 1997. Discourse. London: Routledge.

Mulligan, J. 1998. 'Attitudes towards the NHS and its alternatives', pp. 198-209 in Harrison and New (see above).

NHS Management Inquiry (the Griffith Report). 1983. London: DHSS. 
Ong, P., M. Boaden and S. Cropper. 1997. 'Analysing the medicine-management interface', Journal of Management in Medicine 11, 2, 88-95.

Packwood, T., J. Keen and M. Buxton. 1991. Hospitals in transition. Buckingham: Open University Press.

Pettigrew, A., E. Ferlie and L. McKee. 1992. Shaping strategic change. London: Sage.

Pickersgill, D. and T. Stanton (eds.). 1997. Making sense of NHS complaints and disciplinary procedures. Oxon: Radcliffe.

Pollitt, C., S. Harrison, D. Hunter and G. Marnoch. 1991. 'The reluctant managers: clinicians and budgets in the NHS', Financial Accountability and Management 4, 3, 213-34.

Scott, W. 1995. Institutions and Organization. London: Sage.

Scottish Office. 1997. Designed to care. Edinburgh: HMSO.

Scottish Office Department of Health. 1998. NHS MEL 75.

Shafi, M. and H. Munro. 1998. 'Unscrambling the cultural web', Clinician in management 7, 3, 167-73.

Shortell, S., R. Gillies and K. Devers. 1995. 'Reinventing the American hospital', Millbank Quarterly 73, 2, 131-60.

Strong, P. and J. Robinson. 1990 The NHS under new management. Buckingham: Open University Press.

Suchman, M. 1995. 'Managing legitimacy: strategic and institutional approaches', Academy of Management Review 20, 3-610.

The Observer. 1999. (news report) 22 Aug.

Timmins, N. 1996. The five giants. London: Fontana Press.

Wall, A. 1999. 'Courting' the middle', Health Service Journal, 108, 5640, $22-5$.

Watson, T. and Harriss. 1999. The emergent manager. London: Sage.

Wattis, J. and P. McGinnis. 1999. 'Clinical governance: making it work', Clinician in Management, 8 1, $12-18$.

Weber, M. 1968. Economy and society: an interpretive sociology, ch.3. in G. Roth and C. Wittich (eds.). New York: Bedminster.

Williams, G. and J. Popay. 1994. 'Lay knowledge and the privilege of experience' in J. Gabe, D. Kelleher and G. Williams (eds.), Challenging medicine. London: Routledge.

Williamson, C. 1992. Making sense of the NHS complaints and disciplinary procedures. Oxon: Radcliffe.

Date received 27 January 1999. Date accepted 7 July 1999. 